\title{
The antioxidant action of Polypodium leucotomos extract and kojic acid: reactions with reactive oxygen species
}

\author{
A.J. Gomes ${ }^{1}$, \\ C.N. Lunardi ${ }^{1}$, \\ S. Gonzalez ${ }^{2}$ and \\ A.C. Tedesco ${ }^{1}$
}

\author{
1Departamento de Química, Faculdade de Filosofia, \\ Ciências e Letras de Ribeirão Preto, Universidade de São Paulo, \\ Ribeirão Preto, SP, Brasil \\ ${ }^{2}$ W ellman Laboratories of Photomedicine, Harvard Medical School, \\ Boston, MA, USA
}

\section{Correspondence \\ A.C. Tedesco \\ Departamento de Química \\ FFCLRP, USP \\ Av. Bandeirantes, 3900 \\ 14040-901 Ribeirão Preto, SP \\ Brasil \\ Fax: + 55-16-633-8151 \\ E-mail: tedesco@ ffclrp.usp.br \\ Research supported by CAPES, \\ FAPESP, CNPq and FINEP.}

Received January 29, 2001

Accepted August 13, 2001

\section{Abstract}

Two natural products Polypodium leucotomos extract (PL) and kojic acid (KA) were tested for their ability to scavenge reactive oxygen species $\left({ }^{\bullet} \mathrm{OH},{ }^{\bullet} \mathrm{O}_{2}{ }^{-}, \mathrm{H}_{2} \mathrm{O}_{2},{ }^{1} \mathrm{O}_{2}\right)$ in phosphate buffer. Hydroxyl radicals were generated by the Fenton reaction, and the rate constants of scavenging were $1.6 \times 10^{9} \mathrm{M}^{-1} \mathrm{~s}^{-1}$ for KA and $1.0 \times 10^{9} \mathrm{M}^{-1} \mathrm{~s}^{-1}$ for PL, similar to that of ethanol $\left(1.4 \times 10^{9} \mathrm{M}^{-1} \mathrm{~s}^{-1}\right)$. With superoxide anions generated by the xanthine/hypoxanthine system, KA and PL (0.2-1.0 $\mathrm{mg} / \mathrm{ml}$ ) inhibited $\bullet^{-} \mathrm{O}_{2}$-dependent reduction of nitroblue tetrazolium by up to 30 and $31 \%$, respectively. In the detection of ${ }^{1} \mathrm{O}_{2}$ by rose bengal irradiation, PL at $1.0 \mathrm{mg} / \mathrm{ml}$ quenched singlet oxygen by $43 \%$ relative to azide and KA by $36 \%$. The present study demonstrates that PL showed an antioxidant effect, scavenging three of four reactive oxygen species tested here. Unlike KA, PL did not significantly scavenge hydrogen peroxide.

\section{Introduction}

Reactive oxygen species (ROS) (including superoxide anion ${ }^{\bullet} \mathrm{O}_{2}^{-}$, hydroxyl radical - $\mathrm{OH}$, singlet oxygen ${ }^{1} \mathrm{O}_{2}$, and hydrogen peroxide $\mathrm{H}_{2} \mathrm{O}_{2}$ ) have been considered to be important agents of aging and various human diseases $(1,2)$, such as cancer, heart diseases, multiple sclerosis, Parkinson's disease, autoimmune disease, stroke, and others. Among the various radicals, the hydroxyl radical is presumed to play a central role due to its strong activity (3). The use of antioxidants that can scavenge ROS has been studied by evaluating its potential and therapeutic ap-

\section{Key words}

- Polypodium leucotomos extract

- Kojic acid

- Antioxidant

- Reactive oxygen species 
tive effect of free radical scavengers against the side effects of phototoxicity on normal tissue has been frequently investigated $(5,6)$. Six kinds of scavengers (L-ascorbic acid, reduced glutathione, $\alpha$-tocopherol, retinol, uric acid and cystine) showed a protective effect on normal tissue when injected intraperitoneally. A wide range of antioxidants, both natural and synthetic, has been proposed for use in the treatment of many human diseases. Among naturally occurring antioxidants, superoxide dismutase (7), $\alpha$ tocopherol (8), ascorbic acid $(9,10)$, catalase (11), glutathione $(12,13)$, and carotenoids (14) have been receiving considerable attention. Thiols (N-acetylcysteine) (15-17), xanthine oxidase inhibitors (allopurinol, oxypurinol) $(18,19)$, Trolox C (20), and probucol (21) have been used as synthetic molecules.

In the present investigation we studied the antioxidant properties of two natural products, Polypodium leucotomos extract and kojic acid, a well-known antioxidant agent against ROS.

The first natural product evaluated in this study was an extract from Polypodium leucotomos (PL) that has been used in Central America for the treatment of several phlogistic disorders, including skin-associated inflammatory problems (psoriasis, atopic dermatitis) $(22,23)$. PL has shown an antioxidant action in several studies (24).

The other natural antioxidant studied was kojic acid (KA), a fungal metabolite produced by some species of Aspergillus, Penicillium and Acetobacter, which was first isolated from Aspergillus in 1907. It is a transparent crystalline particulate substance highly soluble in water, ethanol and acetone. KA of high purity (>99\%) and known structure is obtained from Aspergillus and is used for topical application $(25,26)$. In the present study we investigated the inhibitory effect of $\mathrm{PL}$ and KA separately against $\mathrm{ROS}\left(\bullet^{\circ} \mathrm{OH}\right.$, ${ }^{-} \mathrm{O}_{2}^{-}, \mathrm{H}_{2} \mathrm{O}_{2}$ and ${ }^{1} \mathrm{O}_{2}$ ) in $10 \mathrm{mM}$ phosphate buffer.

\section{Material and Methods}

\section{Reagents}

2-Deoxy-D-erythro-pentose (deoxyribose), hypoxanthine, xanthine oxidase, nitroblue tetrazolium (NBT), $\mathrm{Fe}\left(\mathrm{SO}_{4}\right)_{2}\left(\mathrm{NH}_{4}\right)_{2}$, guaiacol, superoxide dismutase (SOD), horseradish peroxidase (HPO) type II, 7hydroxy-6-methoxy-2H-1-benzopyran-2-one (scopoletin), rose bengal, histidine, n,n-dimethyl-4-nitroso-aniline (RNO) and 2-thiobarbituric acid (TBA) were purchased from Sigma (St. Louis, MO, USA). KA was from Aldrich Chemical Co. Inc. (Milwaukee, WI, USA). Hydrogen peroxide was from RiedeldeHaen (Darmstadt, Germany). Potassium hydroxide and sodium hydroxide were from Merck (Darmstadt, Germany). PL extract was obtained from Laboratories Cantabria (Industrial Farmaceutica Cantabria, Madrid, Spain; lot 009314). All other reagents were of the highest quality available from Nuclear Chemical Co. (São Paulo, SP, Brazil).

\section{Fractionation of the Polypodium leucotomos extract}

PL extract was treated as described by Tuominen et al. (23) (Figure 1). The antioxidant properties of the low molecular weight fraction isolated by this procedure were evaluated against $\operatorname{ROS}\left(\cdot \mathrm{OH},{ }^{\bullet} \mathrm{O}_{2}^{-}, \mathrm{H}_{2} \mathrm{O}_{2}\right.$ and $\left.{ }^{1} \mathrm{O}_{2}\right)$.

\section{Hydroxyl radical generation}

The hydroxyl radicals were generated by incubating the following reagents at the indicated concentrations at $37^{\circ} \mathrm{C}$ for $60 \mathrm{~min}$ and are known as a Fenton system: $10 \mathrm{mM}$ $\mathrm{KH}_{2} \mathrm{PO}_{4}-\mathrm{KOH}, \mathrm{pH} 7.4,20-100 \mu \mathrm{M}$ Fe$\left(\mathrm{SO}_{4}\right)_{2}$ $\left(\mathrm{NH}_{4}\right)_{2}$-EDTA, $1.42 \mathrm{mM} \mathrm{H}_{2} \mathrm{O}_{2}, 0.0-1.0 \mathrm{mg} /$ $\mathrm{ml}$ antioxidant and $2.8 \mathrm{mM}$ deoxyribose in a final volume of $1.0 \mathrm{ml}$. The iron salt was premixed with a chelator before addition to the reaction mixture. The extent of deoxyri- 
bose degradation by the formed hydroxyl radicals was measured directly from the aqueous phase by the TBA method as described below (27-29).

TBA test: $1.0 \mathrm{ml}$ TBA $(1 \%, \mathrm{w} / \mathrm{v}$, in 0.05 $\mathrm{M} \mathrm{NaOH}$ ) and $1.0 \mathrm{ml} 2.8 \%(\mathrm{w} / \mathrm{v})$ trichloroacetic acid were added to glass tubes containing the reaction mixture. The tubes were heated at $100^{\circ} \mathrm{C}$ for $15 \mathrm{~min}$ and, after cooling, the chromogen formed was extracted with $3 \mathrm{ml} \mathrm{n}$-butanol. The values of absorbance measured at $532 \mathrm{~nm}$ were recorded for each tube. The data were treated in plots of $1 / \mathrm{Abs}_{532}$ versus concentration to obtain the quenching rate constants $\left(K_{\mathrm{S}}\right)$ as described by Halliwell and co-workers $(27,28)$. Similar measurements were made on two reference compounds (ethanol and ascorbic acid) and the results agreed with those reported in the literature $(28,29)$.

Hydroxyl radicals were generated by the Fenton reaction, which can be described by the following scheme:

Fenton system and TBA test:

$\mathrm{Fe}^{2+}$-EDTA $+\mathrm{O}_{2} \Delta \mathrm{Fe}^{3+}$-EDTA $+\mathrm{O}_{2}^{-}$(Eq. 1)

$2 \mathrm{O}_{2}^{-}+2 \mathrm{H}^{+} \rightarrow \mathrm{H}_{2} \mathrm{O}_{2}+\mathrm{O}_{2}$

(Eq. 2)

$\mathrm{Fe}^{2+}$-EDTA $+\mathrm{H}_{2} \mathrm{O}_{2} \rightarrow \mathrm{OH}^{-}+$

$\cdot \mathrm{OH}+\mathrm{Fe}^{3+}$-EDTA

$\cdot \mathrm{OH}+$ deoxyribose $\rightarrow$ fragments

$\stackrel{\text { heat TBA plus acid }}{\longrightarrow}$ MDA

(Eq. 4)

$2 \mathrm{TBA}+\mathrm{MDA} \rightarrow$ chromogen

(Eq. 5)

\section{Superoxide anion profile}

Superoxide anion radicals were produced by using the hypoxanthine-xanthine oxidase system $(27,30,31)$. The composition of the reaction mixture $(1.0 \mathrm{ml})$ was as follows: 50 $\mathrm{mM} \mathrm{KH}{ }_{2} \mathrm{PO}_{4}-\mathrm{KOH}$, pH 7.4, 1 mM EDTA, $100 \mu \mathrm{M}$ hypoxanthine, and $100 \mu \mathrm{M}$ NBT. The reaction was started by adding 0.066 units of xanthine oxidase freshly diluted in 100 $\mu \mathrm{l}$ of phosphate buffer. All measurements were performed in triplicate. ${ }^{\cdot} \mathrm{O}_{2}{ }^{-}$production was evaluated spectrophotometrically by monitoring the reduction of NBT to nitroblue diformazan at $560 \mathrm{~nm} \mathrm{(31).}$

The generation of ${ }^{\circ} \mathrm{O}_{2}^{-}$was quantitatively estimated as a function of increasing antioxidant concentration $(0.0$ to $1.0 \mathrm{mg} / \mathrm{ml})$ and by recording the decrease in absorbance at $560 \mathrm{~nm}$. The results are expressed as percent inhibition of NBT reduction by PL (30\%) and KA (31\%) using SOD (99\%) as a reference compound.

Control experiments were performed to determine whether PL and KA themselves directly reduce NBT or inhibit xanthine oxidase. Thus, the compounds were added to solutions containing $100 \mu \mathrm{M}$ NBT in phosphate buffer, and absorbance was measured at $550 \mathrm{~nm}$. Their

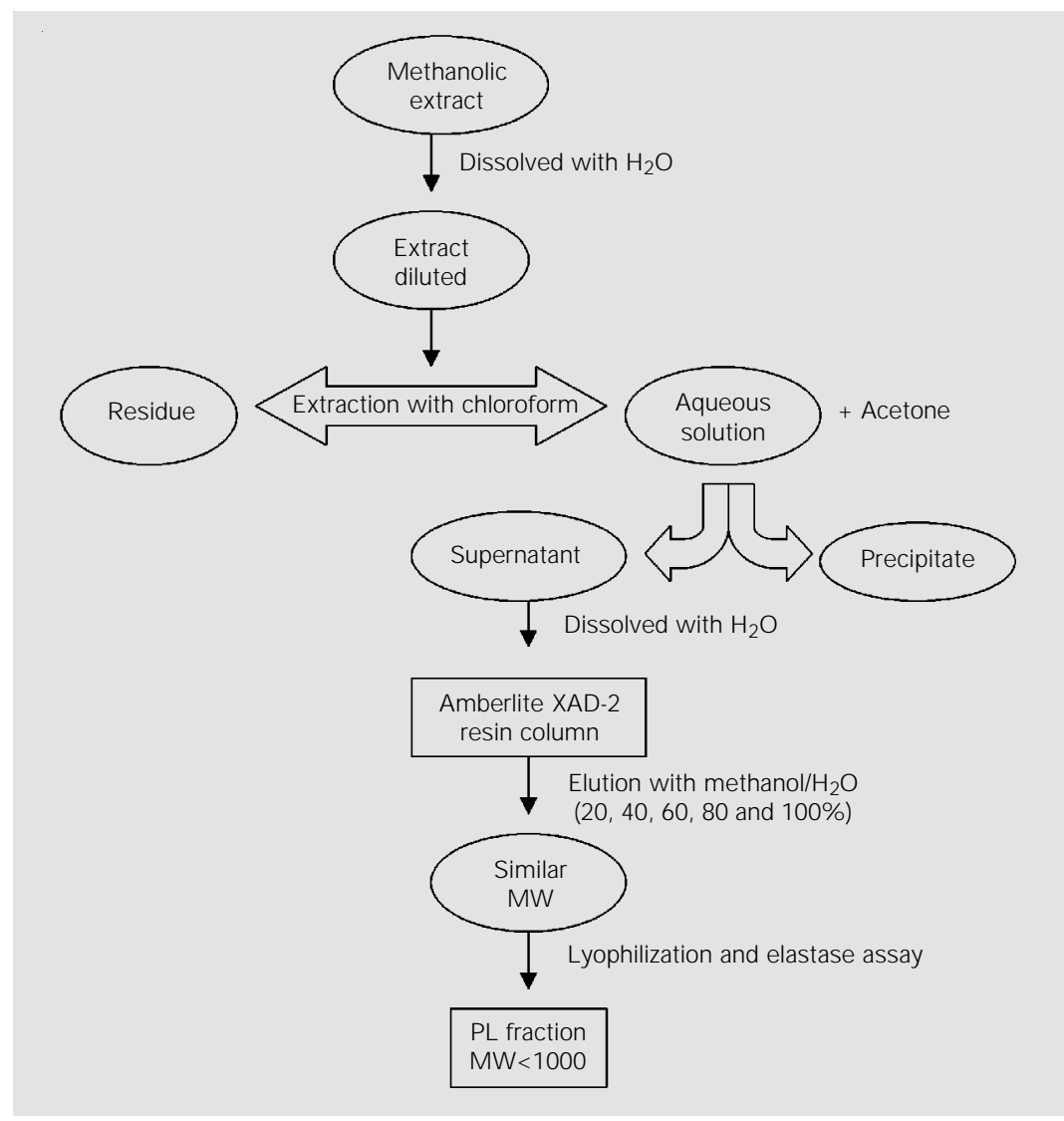

Figure 1. The Polypodium leucotomos extract (PL) obtained from Industrial Farmaceutica Cantabria S.A., Madrid, Spain, was treated as described by Tuominen et al. (23). 
action on xanthine oxidase was tested by measuring uric acid formation under the conditions given in the previous paragraph but with xanthine as substrate, and absorbance was measured at $295 \mathrm{~nm}$ (15-min incubation, $25^{\circ} \mathrm{C}$ ). The activity of PL and KA in the presence of NBT showed no reduction of this compound. Results are expressed as percent inhibition of uric acid production. The activity of the generation of the uric acid system alone was $0.385 \pm 0.007 \mathrm{Abs}_{295} \mathrm{U} /$ min and no generation of uric acid was observed in the presence of either compound tested (PL and KA: 0.1 and $0.3 \%$ of inhibition, respectively).

\section{Hydrogen peroxide assay}

Hydrogen peroxide $\left(\mathrm{H}_{2} \mathrm{O}_{2}\right)$ was detected by the scopoletin peroxidase assay $(27,32)$. Scopoletin $(5 \mu \mathrm{M})$ was added to a 1-cm light path cuvette containing $50 \mu \mathrm{l}$ of $1.0 \mathrm{mg} / \mathrm{ml}$ HPO and the antioxidants PL and KA ( 0.0 to $0.1 \mathrm{mg} / \mathrm{ml}$ ) in $150 \mathrm{mM} \mathrm{KH} \mathrm{PO}_{4}-\mathrm{KOH}$ buffer, $\mathrm{pH}$ 7.4. The cuvettes were maintained for $5 \mathrm{~min}$ at $37^{\circ} \mathrm{C}(27)$, amounts of $\mathrm{H}_{2} \mathrm{O}_{2}(0.1$ $\mathrm{mM}$ ) were added and $\mathrm{H}_{2} \mathrm{O}_{2}$ was quantified after $5 \mathrm{~min}$ of incubation using a fluorescence spectrophotometer (32). The excitation light was set at $350 \mathrm{~nm}$. The intensity of the emission fluorescence at $460 \mathrm{~nm}$ was monitored and recorded continuously with a HITACHI F-4500 spectrofluorometer. The measurement was obtained in triplicate and the system was standardized in the absence of antioxidants with a known amount of peroxide $(27,32)$.

\section{Singlet oxygen assay}

Irradiation was performed using a Surulite I-10 Nd-YAG laser system from Continuum (Santa Clara, CA, USA) operating at 355 $\mathrm{nm}, 8 \mathrm{~ns}$ per pulse at $10 \mathrm{~Hz}$. The absolute energies at this wavelength range from 130 to $150 \mathrm{~mJ}$ per pulse. This light was used to pump a SLOPO laser from Continuum oper- ating at $545 \mathrm{~nm}$. The sample was placed in a standard $10-\mathrm{mm}$ quartz cuvette cell holder at a distance of approximately $60 \mathrm{~cm}$ from the irradiation source. The laser beam (circular profile with a diameter of about $6 \mathrm{~mm}$ ) was directed at the geometric center of the quartz cuvette. The pulse energy was typically 5 $\mathrm{mJ} /$ pulse as measured with a Field Master Power-meter from Coherent (Auburn, CA, USA) with an L30 $\mathrm{V}$ head. The maximum irradiation time was $60 \mathrm{~s}$. The laser energy was monitored throughout the course of the experiment.

The production of ${ }^{1} \mathrm{O}_{2}$ was obtained using a photosensitized method proposed by Kraljic and El Mohsni (33). A solution of 50 $\mu \mathrm{M}$ RNO in $50 \mathrm{mM}$ phosphate buffer, $\mathrm{pH}$ 7.0, was mixed with $10 \mathrm{mM}$ histidine used as a selective acceptor of ${ }^{1} \mathrm{O}_{2}$, leading to RNO degradation. Rose bengal $(10 \mu \mathrm{M})$ was used as photosensitizer. These solutions were irradiated with $545 \mathrm{~nm}$ light from an $\mathrm{Nd}$ YAG/OPO laser and the subsequent bleaching of RNO was recorded spectrophotometrically at $440 \mathrm{~nm}$. The scavenging potential of PL was compared with that of the known ${ }^{1} \mathrm{O}_{2}$ scavenger $\mathrm{NaN}_{3}$ used as reference compound. The results for PL and KA (absence of $\mathrm{NaN}_{3}$ ) were obtained in triplicate and the inhibition of ${ }^{1} \mathrm{O}_{2}$ production was expressed as percent of control values (33-35).

The reaction between histidine and ${ }^{1} \mathrm{O}_{2}$ results in the formation of a transannular peroxide that can bleach RNO (which can be followed at $440 \mathrm{~nm}$ ). In the absence of histidine, there is no measurable loss of RNO, thus neither ${ }^{3} \mathrm{~S}$ nor ${ }^{1} \mathrm{O}_{2}$ formed in the system can cause the secondary intermediate $\left(\mathrm{AO}_{2}\right)$ (transannular peroxide), which oxidizes RNO (33).

$$
\begin{aligned}
& \mathrm{S}+\mathrm{hv} \rightarrow{ }^{1} \mathrm{~S}^{*} \rightarrow{ }^{3} \mathrm{~S} \\
& { }^{3} \mathrm{~S}+\mathrm{O}_{2} \rightarrow \mathrm{S}+{ }^{1} \mathrm{O}_{2} \\
& { }^{1} \mathrm{O}_{2}+\mathrm{A} \rightarrow\left(\mathrm{AO}_{2}\right) \rightarrow \mathrm{AO}_{2} \\
& \left(\mathrm{AO}_{2}\right)+\mathrm{RNO} \rightarrow-\mathrm{RNO}+\text { products } \\
& \mathrm{A}=\text { histidine }
\end{aligned}
$$




\section{Results and Discussion}

The first ROS studied was the hydroxyl radical, a powerful oxidant and one of the most deleterious species produced by the Fenton/Haber-Weiss reaction in all biological systems. Our results for the compounds studied are shown in Table 1 . The values obtained for the two compounds in buffer medium (KA and PL) showed a $K_{\mathrm{S}}$ value of about the same order of magnitude as ethanol and ascorbic acid, both powerful hydroxyl radical scavengers.

None of the compounds interfered with the TBA test, since they did not alter the color formation when they were added at the end of incubation with the TBA reagents instead of being included in the reaction mixtures. Possible formation of peroxides leading to additional color formation during the heating step did not influence the results (27).

We also investigated the ability of PL and KA to scavenge superoxide anions. The ability of PL to inhibit the generation of ${ }^{\bullet} \mathrm{O}_{2}{ }^{-}$was monitored by the NBT assay with the formation of diformazan (31), as shown in Figure 2.

The property of diluted aqueous extracts of $\mathrm{PL}$ and $\mathrm{KA}$ of inhibiting ${ }^{-\mathrm{O}_{2}}{ }^{-}$-dependent NBT reduction can be seen in these plotted graphs. It should be noted that PL and KA showed no evidence of production of ${ }^{\circ} \mathrm{O}_{2}^{-}$ itself in the absence of the generation system. In the presence of buffer medium, PL showed a substantial $31 \%$ reduction in the detection of ${ }^{-\mathrm{O}_{2}}{ }^{-}$and KA showed a $30 \%$ reduction at $1.0 \mathrm{mg} / \mathrm{ml}$. All measurements were compared with control experiments using SOD as a reference scavenger showing 99\% inhibition. These results show that PL and KA could act directly on ${ }^{-} \mathrm{O}_{2}{ }^{-}$leading to its inactivation at the beginning of the ROS cycle generation.

Hydrogen peroxide, like superoxide, is not particularly reactive with most biologically important molecules, but is an intracel- lular precursor of ${ }^{\bullet} \mathrm{OH}$. Produced in the presence of different concentrations of antioxidant compounds, the remaining amounts of hydrogen peroxide present in the medium were determined by the scopoletin peroxidase assay. The data concerning the antioxidant activity of PL and KA against hydrogen peroxide are summarized in Figure 3.

When KA was tested in the 0.0 to $1.0 \mathrm{mg} /$ $\mathrm{ml}$ range using the scopoletin peroxidase system a saturation effect was observed. KA was also tested in the 0.0 to $0.1 \mathrm{mg} / \mathrm{ml} \mathrm{con-}$ centration range, exhibiting $2.9 \%$ inhibition.

Table 1. Quenching activity of hydroxyl radical by $\mathrm{PL}$ and KA.

\begin{tabular}{lc}
\hline Antioxidant & $\begin{array}{r}\mathrm{K}_{\mathrm{S}} \text { (deoxyribose assay) } \\
\left(\mathrm{M}^{-1} \mathrm{~s}^{-1} \times 10^{9}\right)\end{array}$ \\
\hline $\mathrm{KA}$ & $1.6 \pm 0.3$ \\
$\mathrm{PL}$ & $1.0 \pm 0.4$ \\
Ethanol & $1.4 \pm 0.2$ \\
Ascorbic acid & $7.2 \pm 0.3$ \\
\hline
\end{tabular}

Data are reported as means \pm SD for 3 experiments. $\mathrm{KA}=$ kojic acid; $\mathrm{PL}=$ Polypodium leucotomos extract.
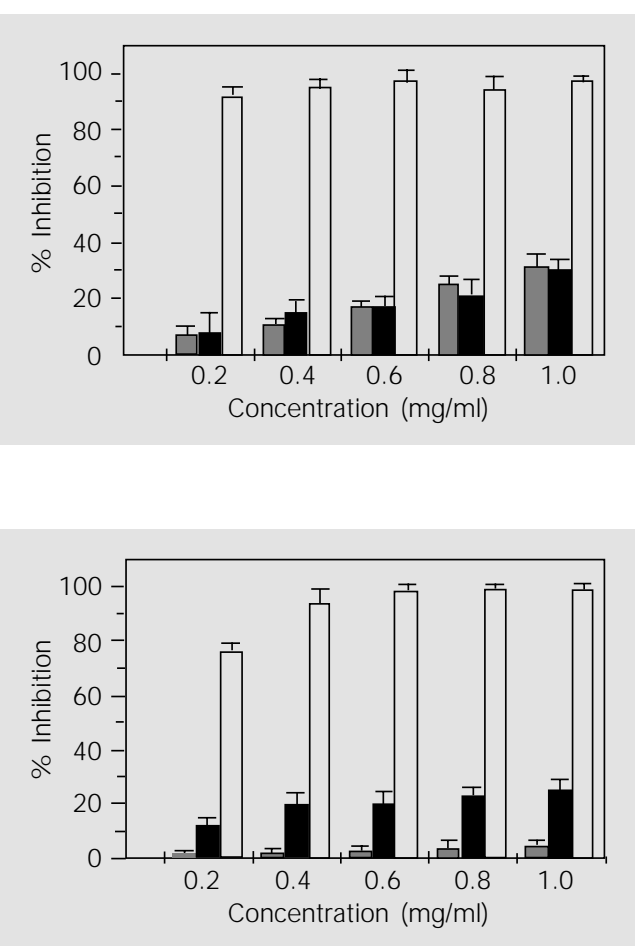

Figure 2. Inhibitory effect of Polypodium leucotomos extract (PL) and kojic acid (KA) (0.0 to $1.0 \mathrm{mg} / \mathrm{ml}$ ) on the reduction of nitroblue tetrazolium by superoxide anion radical $\left(\mathrm{O}_{2}^{-}\right)$generated by the hypoxanthine-xanthine oxidase system. PL (gray bars), KA (black bars), and SOD (light gray bars) used as control.

Figure 3. Inhibitory effect of Polypodium leucotomos extract (PL) and kojic acid (KA) (0.0 to $0.1 \mathrm{mg} / \mathrm{ml}$ ) on $\mathrm{H}_{2} \mathrm{O}_{2}$. PL (gray bars), KA (black bars), and catalase (light gray bars) used as control were detected by the scopoletin assay. 
PL as an antioxidant compound was studied in the concentration range of 0.0 to $0.1 \mathrm{mg} /$ $\mathrm{ml}$, with $2.5 \%$ inhibition of $\mathrm{H}_{2} \mathrm{O}_{2}$ in buffer medium. All measurements were compared to control experiments using catalase as a reference scavenger (99\% inhibition).

Among all ROS studied, ${ }^{\circ} \mathrm{OH}$ possesses a rate constant of the order of $10^{10} \mathrm{M}^{-1} \mathrm{~s}^{-1}$, and is difficult to measure by spectroscopic methods. However, based on their quenching rate constants (Table 1), the antioxidant activities of PL and KA in quenching ${ }^{\circ} \mathrm{OH}$ can be determined. Although the antioxidant action of PL and KA on $\mathrm{H}_{2} \mathrm{O}_{2}$ was of low efficiency, both antioxidants studied were effective against ${ }^{\circ} \mathrm{O}_{2}{ }^{-}$and ${ }^{\circ} \mathrm{OH}$ at the beginning and at the end of the Fenton reaction system.

Over the last few years, many studies have reported that ROS production can be used for the treatment of neoplastic diseases, a procedure known as photodynamic therapy. The two major species produced during a photosensitization process are ${ }^{1} \mathrm{O}_{2}$ and ${ }^{\bullet} \mathrm{O}_{2}^{-}$. Thus, ${ }^{\bullet} \mathrm{O}_{2}{ }^{-}$quenching implies a reduction of $\mathrm{H}_{2} \mathrm{O}_{2}$ and $\bullet \mathrm{OH}$.

Another ROS evaluated in the present study was singlet oxygen $\left({ }^{1} \mathrm{O}_{2}\right)$. In biological systems, ${ }^{1} \mathrm{O}_{2}$ is generated by absorption of incident light at specific wavelengths by excitable endogenous or exogenous molecules

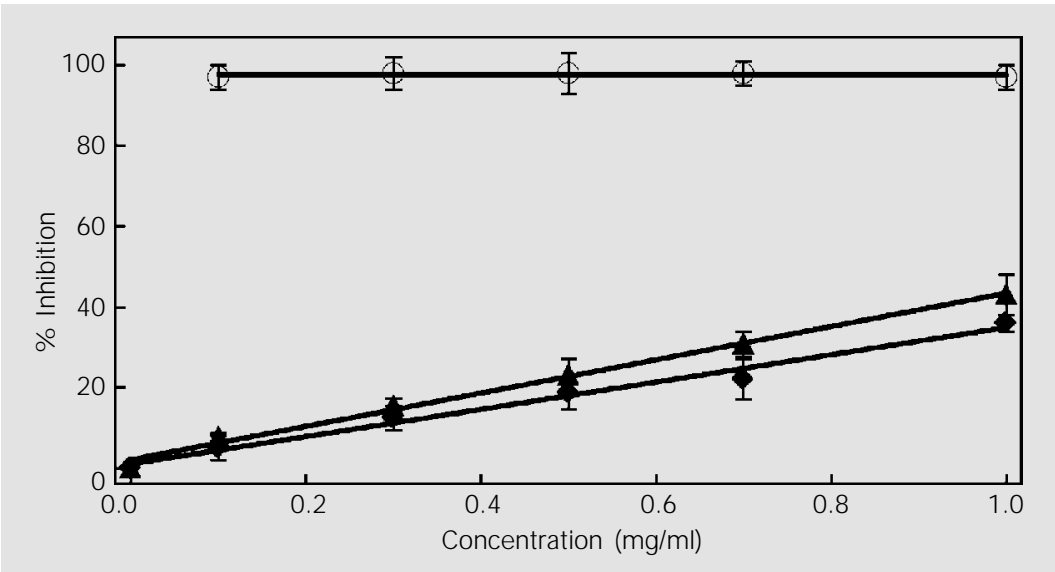

Figure 4. Inhibitory effect of Polypodium leucotomos extract (triangles) and kojic acid (lozenges) $(0.0$ to $1.0 \mathrm{mg} / \mathrm{ml})$ on singlet oxygen detected by bleaching of $n, n$-dimethyl-4nitroso-aniline. Azide (circles) was used as control. known as photosensitizers. A large number of sensitizers occur naturally in organisms (riboflavin, 4-thiouridine, etc.), but many others need to be added exogenously to the system. The energy of the triplet excited state for the sensitizers is then transferred to an adjacent triplet oxygen molecule, transforming molecular oxygen to the singlet oxygen (1).

When the ground state $\mathrm{O}_{2}$ is excited to a higher energy state, singlet ${ }^{1} \mathrm{O}_{2}$ is formed. This form of oxygen is also a harmful species to biological systems and its production under controlled conditions has been extensively studied in the last two decades as the basis of an alternative approach to the treatment of neoplastic diseases known as photodynamic therapy (36).

In our studies, the formation of singlet oxygen was detected by the method of Kraljic and El Mohsni (33), whereby solutions containing RNO and a photosensitizer (rose bengal) were irradiated with $545 \mathrm{~nm}$ light isolated from an Nd-YAG/OPO laser. The subsequent bleaching of RNO was recorded spectrophotometrically at $440 \mathrm{~nm}$.

Figure 4 shows that increased concentrations of the antioxidant species (PL and KA) reduced the photobleaching rate of RNO. On the basis of these results, we conclude that PL was the most effective quencher of singlet oxygen $(43 \%)$, followed by KA, with $36 \%$ inhibition. All measurements were compared to control experiments using sodium azide as a reference ${ }^{1} \mathrm{O}_{2}$ quencher with $99 \%$ inhibition.

Our results show that PL and KA had an efficient antioxidant activity against three of the four $\operatorname{ROS}\left({ }^{\circ} \mathrm{OH},{ }^{\bullet} \mathrm{O}_{2}{ }^{-}\right.$and $\left.{ }^{1} \mathrm{O}_{2}\right)$ tested here and showed a low efficiency in hydrogen peroxide scavenging. The scavenger activity observed against superoxide anion is particularly important because, despite its mild reactive property (a rate constant of $10^{-2} \mathrm{M}^{-1}$ $\mathrm{s}^{-1}$ ), it is a potential precursor of the aggressive hydroxyl radical produced in the Fenton and Haber-Weiss reaction. The same could 
be assumed about its action against hydroxyl radicals.

Another ROS evaluated in the present study was singlet oxygen. Both antioxidants tested showed efficacy in quenching this species. These ROS are produced routinely during the photodynamic therapy of neoplastic diseases and others such as diabetes and arteriosclerosis. Together with the superoxide anions, these are the two basic species involved in the photosensitization process. Given this, both PL and KA could be used as nontoxic naturally occurring anti- oxidant products during photodynamic therapy blocking the action and side effects of many ROS produced outside the main target, i.e., the neoplastic cells.

\section{Acknowledgments}

This paper is dedicated to the memory of Prof. J.B.S. Bonilha, Professor of Chemistry, specialist in Photochemistry of Organized Media at FFCLRP, Universidade de São Paulo, Ribeirão Preto, SP, Brazil.

\section{References}

1. Tedesco AC, Martinez L \& Gonzalez S (1997). Photochemistry and photobiology of actinic erythema: defensive and reparative cutaneous mechanism. Brazilian J ournal of Medical and Biological Research, 30: 561-575.

2. McCord J M (1985). Oxygen-derived free radicals in postischemic tissue injury. New England J ournal of Medicine, 312: 159164.

3. Wang WF, Luo J , Yao SD, Lian ZR, Zhang J S \& Lin NY (1993). Interaction of phenolic antioxidants and hydroxyl radicals. Radiation Physics and Chemistry, 42: 985991.

4. Kong Q \& Lillehei KO (1988). Antioxidant inhibitors for cancer therapy. Medical Hypotheses, 51: 405-409.

5. Singh K (1997). Oxidants, antioxidants and diseases, a brief review. Indian J ournal of Medical Sciences, 51: 226-230.

6. Chapple IL (1997). Reactive oxygen species and antioxidants in inflammatory diseases. J ournal of Clinical Periodontology, 24: 287-296.

7. Gibson A \& Lilley E (1997). Superoxide anions, free-radical scavengers, and nitrergic neurotransmission. General Pharmacology, 28: 489-493.

8. Liebler DC (1998). Antioxidant chemistry of alpha-tocopherol in biological systems. Roles of redox cycles and metabolism. Subcellular Biochemistry, 30: 301-317.

9. Head KA (1998). Ascorbic acid in the prevention and treatment of cancer. Alternative Medicine Review, 3: 174-186.

10. Halliwell B (1996). Vitamin C: antioxidant or pro-oxidant in vivo? Free Radical Research, 25: 439-454.
11. Sies H (1997). Oxidative stress: oxidants and antioxidants. Experimental Physiology, 82: 291-295.

12. Harding J J , Blakytny R \& Ganea E (1996). Glutathione in disease. Biochemical Society Transactions, 24: 881-884.

13. Meister A (1994). Glutathione, ascorbate, and cellular protection. Cancer Research, 54 (Suppl 7): 1969S-1975S.

14. Edge R, McGarvey DJ \& Truscott TG (1997). The carotenoids as anti-oxidants A review. J ournal of Photochemistry and Photobiology. B, Biology, 41: 189-200.

15. Moldeus $P \&$ Cotgreave IA (1994). Nacetylcysteine. Methods in Enzymology, 234: 482-492.

16. Warren BS \& Slaga TJ (1993). Mechanisms of inhibition of tumor progression. Basic Life Sciences, 61: 279-289.

17. Halliwell B (1991). Drug antioxidant effects. A basis for drug selection? Drugs, 42: 569-605.

18. Xia M, llich P, Dempski R \& Hille R (1997). Recent mechanistic studies of xanthine oxidase. Biochemical Society Transactions, 25: 768-773.

19. Bray RC \& Lowe DV (1997). Towards the reaction mechanism of xanthine oxidase from EPR studies. Biochemical Society Transactions, 25: 762-768.

20. Clemens J A \& Panetta J A (1994). Neuroprotection by antioxidants in models of global and focal ischemia. Annals of the New York Academy of Sciences, 738: 250-256.

21. Mugge A (1998). The role of reactive oxygen species in atherosclerosis. Zeitschrift für Kardiologie, 87: 851-864.

22. J iménez $D$, Naranjo R, Doblaré E, Munoz
C \& Vargas JF (1987). Anapsos, an antipsoriatic drug, in atopic dermatitis. Allergologia et Immunopathologia, 15: 185-189.

23. Tuominen $M$, Bohlin $L$, Lindbon L-O \& Rolfsen W (1991). Enhancing effect of extract of Polypodium leucotomos on the prevention of rejection of skin transplants in mice. Phytotherapy Research, 5: 234236.

24. Gonzalez S, Pathak MA, Cuevas J, Villarubia VG \& Fitzpatrik TB (1997). Topical or oral administration with an extract of Polypodium leucotomos prevents acute sunbum and psoralen-induced phototoxic reactions as well as depletion of Langerhans cells in human skin. Photodermatology, Photoimmunology and Photomedicine, 13: 50-60.

25. Niwa Y \& Akamatsu H (1991). Kojic acid scavenges free radicals while potentiating leukocyte functions including free radical generation. Inflammation, 15: 303-315.

26. Nakagawa M \& Kawai K (1995). Contact allergy to kojic acid in skin care products. Contact Dermatitis, 32: 9-13.

27. Paya M, Halliwell B \& Hoult J RS (1992). Interactions of a series of coumarins with reactive oxygen species. Biochemical Pharmacology, 44: 205-214.

28. Halliwell B, Gutteridge J MC \& Aruoma OI (1987). The deoxyribose method: A simple "test-tube" assay for determination of rate constants for reactions of hydroxyl radical. Analytical Biochemistry, 165: 215-219.

29. Halliwell B \& Gutteridge J MC (1981). Formation of a thiobarbituric-acid-reactive substance from deoxyribose in the pres- 
ence of iron salts. FEBS Letters, 128: 347352.

30. Aruoma OI, Halliwell B, Hoey BM \& Butler J (1989). The antioxidant action of $\mathrm{N}$ acetylcysteine: its reaction with hydrogen peroxide, hydroxyl radical, superoxide and hypochlorous acid. Free Radical Biology and Medicine, 6: 593-597.

31. Bielski BHJ , Shlue GG \& Bajuk S (1980). Reduction of nitro blue tetrazolium by $\mathrm{CO}_{2}{ }^{-}$and $\mathrm{O}_{2}{ }^{-}$radicals. J ournal of Physical Chemistry, 84: 830-833.
32. Root RK, Metcalf J , Oshino N \& Change B (1975). $\mathrm{H}_{2} \mathrm{O}_{2}$ Release from human granulocytes during phagocytosis. J ournal of Clinical Investigation, 55: 945-955.

33. Kraljic I \& El Mohsni S (1978). A new method for the detection of singlet oxygen in aqueous solutions. Photochemistry and Photobiology, 28: 577-581.

34. Allen MT, Lynch $M$, Lagos $A$, Redmond RW \& Kochevar IE (1991). A wavelength dependent mechanism for rose bengalsensitized photoinhibition of red cell ace- tylcholinesterase. Biochimica et Biophysica Acta, 1075: 42-49.

35. Gottfried VG, Peled D, Winkelman JW \& Kimel S (1988). Photosensitizers in organized media: singlet oxygen production and spectral properties. Photochemistry and Photobiology, 48: 157-163.

36. Fritzsch C, Goerz G \& Ruzicka T (1998). Photodynamic therapy in dermatology. Archives of Dermatology, 134: 207-214. 